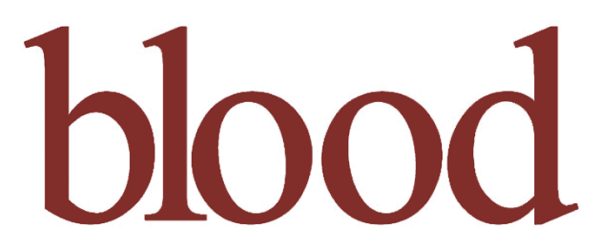

2008 112: 3135-3137

Prepublished online Jun 27, 2008;

doi:10.1182/blood-2008-04-153783

\title{
Thrombocytosis and leukocytosis interaction in vascular complications of essential thrombocythemia
}

Alessandra Carobbio, Guido Finazzi, Elisabetta Antonioli, Paola Guglielmelli, Alessandro M. Vannucchi, Federica Delaini, Vittoria Guerini, Marco Ruggeri, Francesco Rodeghiero, Alessandro Rambaldi and Tiziano Barbui

Updated information and services can be found at:

http://bloodjournal.hematologylibrary.org/cgi/content/full/112/8/3135

Articles on similar topics may be found in the following Blood collections:

Hemostasis, Thrombosis, and Vascular Biology (2496 articles)

Neoplasia (4217 articles)

Brief Reports (1213 articles)

Clinical Trials and Observations (2702 articles)

Information about reproducing this article in parts or in its entirety may be found online at:

http://bloodjournal.hematologylibrary.org/misc/rights.dtl\#repub_requests

Information about ordering reprints may be found online at:

http://bloodjournal.hematologylibrary.org/misc/rights.dtl\#reprints

Information about subscriptions and ASH membership may be found online at:

http://bloodjournal.hematologylibrary.org/subscriptions/index.dtl

Blood (print ISSN 0006-4971, online ISSN 1528-0020), is published semimonthly by the American Society of Hematology, $1900 \mathrm{M} \mathrm{St}$, NW, Suite 200, Washington DC 20036.

Copyright 2007 by The American Society of Hematology; all rights reserved.

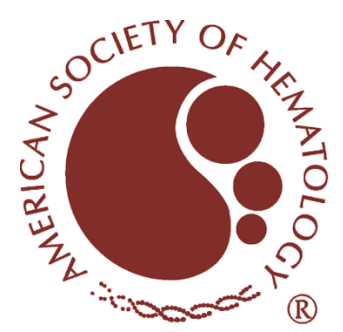




\title{
Brief report
}

\section{Thrombocytosis and leukocytosis interaction in vascular complications of essential thrombocythemia}

\author{
Alessandra Carobbio, ${ }^{1}$ Guido Finazzi, ${ }^{2}$ Elisabetta Antoniolii, ${ }^{3}$ Paola Guglielmelli, ${ }^{3}$ Alessandro M. Vannucchi, ${ }^{3}$ \\ Federica Delaini, ${ }^{1}$ Vittoria Guerini, ${ }^{1}$ Marco Ruggeri, ${ }^{4}$ Francesco Rodeghiero, ${ }^{4}$ Alessandro Rambaldi, ${ }^{1}$ and Tiziano Barbui ${ }^{1}$ \\ Departments of ${ }^{1} \mathrm{Hematology}$ and ${ }^{2}$ Transfusion Medicine, Ospedali Riuniti di Bergamo, Bergamo; ${ }^{3}$ Department of Hematology, Università degli Studi di Firenze, \\ Firenze; and ${ }^{4}$ Department of Hematology, Ospedale San Bortolo, Vicenza, Italy
}

To elucidate the role of thrombocytosis, alone or in combination with standard (age, previous cardiovascular events) and novel (leukocytosis, JAK2 ${ }^{\mathrm{V} 617 \mathrm{~F}}$ mutational status) risk factors, in the cardiovascular events of essential thrombocythemia (ET), we analyzed a cohort of 1063 patients. We found that a platelet count at diagnosis greater than $1000 \times 10 \% / L$ was associated with significantly lower rate of thrombosis in multivariable analysis and, if combined with leukocytes less than $11 \times 10 \%$, pointed to a "low-risk" category with a rate of thrombosis of $1.59 \%$ of patients/year. On the contrary, the highest risk category (thrombosis rate, $2.95 \%$ of patients/year) was constituted of patients with leukocytosis, lower platelet count, and a $J A K 2^{\mathrm{V} 617 \mathrm{~F}}$ mutated genotype in most cases $(77 \%$ vs $26 \%$ in the low-risk group), independently from standard risk factors. These data challenge the theory that elevated platelet count increases thrombosis risk in ET and suggest prospective clinical trials to support this hypothesis. (Blood. 2008;112:3135-3137)

\section{Introduction}

Thrombosis is a major complication in essential thrombocythemia (ET). Therapy is driven by patient cardiovascular risk, conventionally defined by age and history of previous thrombosis. ${ }^{1}$ Recently, leukocytosis and $J A K 2^{\mathrm{V} 617 \mathrm{~F}}$ mutation have been proposed as disease related prognostic factors. ${ }^{2}$ In contrast, the link between thrombocytosis and vascular complications remains uncertain. ${ }^{3}$ Nevertheless, expert-produced guidelines recommend that therapy in ET should be aimed at correcting thrombocytosis. ${ }^{4,5}$

In order to explore the respective role of conventional and new risk factors predicting the incidence of vascular complications, we examined a large cohort of 1063 ET patients and report here the prognostic interaction between patient related and disease related risk factors including platelet and leukocyte counts, and $J A K 2^{\mathrm{V} 617 \mathrm{~F}}$ mutational status.

\section{Methods}

The study cohort consisted of 1063 patients with ET diagnosed according to the Polycythemia Vera Study Group and, since 2000, World Health Organization criteria and followed in 3 Italian academic institutions (Ospedali Riuniti di Bergamo, Azienda Ospedaliera-Universitaria Careggi, Florence, and Ospedale San Bortolo, Vicenza). Permission was obtained from the institutional review boards to review the medical records. This study was conducted in accordance with the Declaration of Helsinki.

There were 709 females and 354 males (ratio 2:1) and median age at diagnosis was 55 years (range 8 to 95 years). Median platelet and leukocyte counts were $806 \times 10^{9} / \mathrm{L}\left(376-3000 \times 10^{9} / \mathrm{L}\right)$ and $8.8 \times 10^{9} / \mathrm{L}(3.3-$ $35 \times 10^{9} / \mathrm{L}$ ), respectively. $J A K 2^{\mathrm{V} 617 \mathrm{~F}}$ mutation was found in 465 of 860 patients $(54 \%)$ and $5 \%$ of them had greater than $50 \% J A K 2^{\mathrm{V} 617 \mathrm{~F}}$ allele.

A total of 193 of the patients (18\%) had a prior history of thrombosis, which was made up of an arterial event in 133 (69\%) and venous thrombosis in $60(31 \%)$. Major hemorrhagic events were reported in 38 patients of $1063(3.6 \%)$.

Patients were classified as being at low- or high-risk for thrombosis according to standard risk factors (age $\geq 60$ years and/or a previous major thrombotic event). Low risk patients $(\mathrm{n}=517,49 \%)$ were followed with no cytoreductive therapy whereas high-risk patients $(n=546,51 \%)$ were given cytotoxic drugs, which were hydroxyurea (HU) in the great majority (90\%) of cases and busulfan in a small group of aged patients (10\%). The target of therapy was to keep platelet numbers below $600 \times 10^{9} / \mathrm{L}$. Lowdose aspirin (100 mg daily) was prescribed in 703 patients (66\%) according to the indication of the physician in charge.

Only major vascular thrombotic events were examined, including ischemic stroke, cerebral transient ischemic attacks (TIA), acute myocardial infarction (AMI), peripheral arterial thrombosis (PAT), and venous thromboembolism (VTE). Diagnostic procedures for thrombosis $^{6}$ and $J A K 2^{\mathrm{V} 617 \mathrm{~F}}$ and $M P L^{\mathrm{W} 515 \mathrm{~K} / \mathrm{L}}$ mutations were performed as previously described. ${ }^{7,8}$

Cox multivariable models were evaluated unadjusted and subsequently adjusted for center, sex, standard risk factors (age $\geq 60$ years and/or previous thrombotic event), hemoglobin at diagnosis, use of antiplatelet drugs, chemotherapy, and $J A K 2^{\mathrm{V} 617 \mathrm{~F}}$ status. All probability values were 2 -tailed; $P$ less than or equal to .05 was considered significant.

\section{Results and discussion}

During up to 38 years of follow-up (median 4.8 years), 118 major thrombosis (2.3\% of patients/year) were objectively diagnosed and included 48 ischemic strokes or TIA, 25 AMI, 11 PAT, and 34 VTE. Severe bleeding episodes (gastrointestinal in 80\%) were $39(0.76 \%$ patients/year).

Multivariable analysis confirmed that age and previous thrombosis were independent factors for occlusive events (hazard ratio
Submitted April 29, 2008; accepted June 24, 2008. Prepublished online as Blood First Edition paper, June 27, 2008; DOI 10.1182/blood-2008-04-153783.

The publication costs of this article were defrayed in part by page charge payment. Therefore, and solely to indicate this fact, this article is hereby marked "advertisement" in accordance with 18 USC section 1734.

(C) 2008 by The American Society of Hematology 
From www.bloodjournal.org at BIBLIOTECA BIOMEDICA on October 12, 2009. For personal use only.

Table 1. Multivariable analysis of the relative risk of total thrombosis among 1063 ET patients

\begin{tabular}{|c|c|c|c|c|}
\hline \multirow[b]{2}{*}{ Models } & \multicolumn{2}{|c|}{ Platelet count $^{\star}\left(\times 10^{9} / \mathrm{L}\right)$} & \multicolumn{2}{|c|}{ White blood cell count ${ }^{*}(\times 10 \% / L)$} \\
\hline & 650 to 1000 & More than 1000 & 8.0 to 11.0 & More than 11.0 \\
\hline 1. Unadjusted & $0.7(0.4-1.1) .2$ & $0.5(0.3-0.9) .03$ & $1.3(0.8-1.9) .3$ & $1.7(1.0-2.7) .04$ \\
\hline 2. Variables adjusted & $0.6(0.4-1.0) .1$ & $0.5(0.3-0.8) .01$ & $1.4(0.9-2.1) .2$ & $1.8(1.1-2.9) .02$ \\
\hline 3. JAK2 ${ }^{\mathrm{V} 617 \mathrm{~F}}$ adjusted & $0.6(0.4-1.1) .1$ & $0.6(0.3-1.1) .10$ & $1.5(0.9-2.5) .1$ & $2.0(1.1-3.6) .02$ \\
\hline
\end{tabular}

Data are $\mathrm{HR}(95 \% \mathrm{Cl}) P$ value.

${ }^{*}$ Reference categories: platelet count less than $650 \times 10^{9} / \mathrm{L}$; white blood cell count less than $8 \times 10^{9} / \mathrm{L}$.

Model 1: platelet count (3 categories) or white blood cell count ( 3 categories).

Model 2: model 1 plus center (3 categories), sex (2 categories), standard risk factors: age 60 years or older and/or previous thrombotic event (yes/no), hemoglobin at diagnosis ( 2 categories, median value used as cutoff), white blood cell count or platelet at diagnosis, respectively ( 2 categories, median value used as cutoff), antiplatelets use (yes/no), chemotherapy use (yes/no).

Model 3: model 2 plus JAK2 ${ }^{\mathrm{V} 617 \mathrm{~F}}$ status (yes/no).

$[\mathrm{HR}]=1.7,95 \%$ confidence interval $[\mathrm{CI}]=1.1-2.6, P=.01$; data not shown). None of the above variables influenced the risk for major bleeding.

Table 1 reports the risk estimates given as HR of 2 platelet (Plt) counts and 2 white blood cell (WBC) levels, respectively. Compared with a reference platelet count below $650 \times 10^{9} / \mathrm{L}$, risk estimates were searched in patients presenting with platelet counts ranging from 650 to $1000 \times 10^{9} / \mathrm{L}$ or above $1000 \times 10^{9} / \mathrm{L}$. In this latter group, a significant reduction of the incidence of arterial and venous thrombosis was seen in univariate analysis (unadjusted model) and in the progressively adjusted models including center, gender, standard risk factors, hemoglobin level, leukocyte values, antiplatelet drugs, and chemotherapy. Only when the model was adjusted also for $J A K 2^{\mathrm{V} 617 \mathrm{~F}}$ status was this association reduced and no longer significant $(P=.10)$. Compared with patients with WBC less than $8 \times 10^{9} / \mathrm{L}$, those with WBC above $11 \times 10^{9} / \mathrm{L}$ had a significant higher risk of total thrombosis both in unadjusted analysis and in the progressively adjusted predictive models including $J A K 2^{\mathrm{V} 617 \mathrm{~F}}$ status, that per se was found an independent predictor for thrombosis in this latter model.

To see whether the prognostic risk of thrombosis was not only driven by individual WBC and Plt counts, but also by their interaction, we analyzed 4 groups of patients according to the baseline leukocyte (lower or greater than $11 \times 10^{9} / \mathrm{L}$ ) and platelet (lower or greater than $1000 \times 10^{9} / \mathrm{L}$ ) counts (Table 2 ). In patients presenting with WBC less than $11 \times 10^{9} / \mathrm{L}$ and extreme thrombocytosis (group 1), the annual rate of events was $1.59 \%$ of patients/year and the prevalence of $J A K 2^{\mathrm{V} 617 \mathrm{~F}}$ mutation was $26 \%$. In the other 3 groups the incidence and the relative risk of thrombosis progressively increased, as well as the proportion of $J A K 2$ mutated patients (up to $77 \%$ ).

No difference across groups was demonstrated in terms of conventional risk factor distribution, percentage of $J A K 2^{\mathrm{V} 617 \mathrm{~F}}$ allele burden, and $M P L^{W 515 K / L}$ mutation frequency (found in $3 \%$ of examined patients; data not shown).

Results of this study extend and confirm a number of previous observations concerning the uneven relationship between thrombocytosis and thrombosis in ET. ${ }^{2}$ The novel finding is the inverse relationship between platelet count and thrombosis. Similar results were obtained in an analysis of 1638 polycythemia vera (PV) patients enrolled in the European Collaboration on Low-Dose Aspirin in Polycythemia Vera study. ${ }^{9}$ In this study, time-dependent multivariable analysis showed that patients with PV and thrombocytosis above $500 \times 10^{9} / \mathrm{L}$ had a $30 \%$ lower risk of total thrombosis than patients with less than $300 \times 10^{9} / \mathrm{L}$ (relative risk $[\mathrm{RR}]=0.64, P=.02$ ). In the present ET patient population, results of multivariable analysis argue against a more aggressive use of cytoreductive therapy as the reason for the lower rate of total thrombosis in patients with extreme thrombocytosis. The most likely explanation of this counterintuitive finding is the acquired von Willebrand disease occurring in ET with very elevated platelet count. ${ }^{10}$ The decrease of von Willebrand factor (VWF) protein, due to an increased adsorption of large VWF multimers to platelet surfaces consistent with variant type $2 \mathrm{~A}$ von Willebrand disease, is significantly correlated with the level of thrombocytosis in ET and other myeloproliferative neoplasms. Reduction of the platelet count below $1000 \times 10^{9} / \mathrm{L}$ usually restores the multimeric integrity of the VWF protein with the reversal of the bleeding tendency. Thus, high platelet number is a possible risk factor for major bleeding, ${ }^{10}$ but at the same time, it is protective against thrombosis, as observed in patients with congenital von Willebrand disease. ${ }^{11}$ In addition to acquired von Willebrand disease, bleeding may also be due to biochemical and functional abnormalities of platelets ${ }^{10}$

The other major finding of this study is the interaction of thrombocytosis with leukocyte number and $J A K 2^{\mathrm{V} 617 \mathrm{~F}}$ mutation in predicting the thrombotic risk. The lowest risk has been observed in ET patients with low white blood cell count, high platelet count, and low prevalence of $J A K 2^{\mathrm{V} 617 \mathrm{~F}}$. On the other hand, the typical phenotype of $J A K 2$-mutated ET patients, that is, higher leukocyte and lower platelet count, is associated with the highest thrombotic risk. Even though results of this study deserve to be confirmed by prospective observations, they strengthen the view that overall myeloproliferation rather than platelet count only should be the target of therapy in ET. This is in keeping with Primary Thrombocythemia 1 (PT1) trial results ${ }^{12}$ showing superiority of hydroxyurea

Table 2. Interaction of leukocyte and platelet counts at diagnosis (multivariable model)

\begin{tabular}{|c|c|c|c|c|c|}
\hline Interaction & n (\%) $)^{*}$ & $\begin{array}{c}\text { Rate of vascular event } \\
\text { (\% patients/year) }\end{array}$ & $\begin{array}{l}\text { Low risk } \dagger \\
\text { (\% patients) }\end{array}$ & $\begin{array}{l}J A K 2^{\mathrm{V} 617 F_{\ddagger}} \\
\text { (\% patients) }\end{array}$ & $\begin{array}{c}\text { RR } \\
\text { (Pvalue) }\end{array}$ \\
\hline 1. WBC less than 11 , PIt more than 1000 & $170(16)$ & 1.59 & $95(56)$ & $35(26)$ & 1 \\
\hline 2. WBC less than 11 , Plt less than 1000 & $644(62)$ & 2.26 & $317(49)$ & $304(56)$ & $1.92(.034)$ \\
\hline 3. WBC more than 11 , PIt more than 1000 & $99(9)$ & 2.88 & $41(41)$ & $40(61)$ & $2.38(.026)$ \\
\hline 4. WBC more than 11 , Plt less than 1000 & $130(12)$ & 2.95 & $52(40)$ & $75(77)$ & $2.43(.017)$ \\
\hline
\end{tabular}

WBC and Plt counts are $\times 10^{9} / \mathrm{L}$.

${ }^{*}$ Twenty patients were excluded because of WBC or platelet count data missing at diagnosis.

†Age younger than 60 years and no previous thrombosis; untreated $(90 \%)$.

$\ddagger$ Percentage calculated on 860 patients evaluated for JAK2 $2^{\mathrm{V} 617 \mathrm{~F}}$. 
(panmyelosuppressive drug) over treatment with anagrelide (specific thrombopoietic inhibitor) in reducing arterial events in $J A K 2$-mutated ET patients.

\section{Acknowledgments}

This work was supported by funding from Associazione Italiana per la Ricerca sul Cancro (AIRC; V.G., Schenker-Erico Ghezzi fellowship and grants to A.M.V.); Fondazione Italiana per la Ricerca sul Cancro (FIRC; A.C. fellowship); European LeukemiaNet Sixth Framework Program LSH-2002-2.2.0-3; Ricerca finalizzata 2005 - IRCCS Policlinico "San Matteo"; National Institutes of Health Clinical Trails Consortium Myeloproliferative Disease Research Consortium grant; MIUR-Cofin 2006067001_003 to A.M.V.; Associazione Paolo Belli and Associazione Italiana Lotta alla Leucemia (AIL), sezione Paolo Belli.

\section{Authorship}

Contribution: A.C. performed research, analyzed and interpreted data, and wrote the manuscript; G.F. performed research and wrote the manuscript; E.A. performed laboratory experiments and collected data; P.G. performed laboratory experiments; A.M.V. wrote the manuscript and supervised laboratory experiments; F.D., M.R., and F.R. collected clinical data; V.G. performed laboratory experiments; A.R. performed research; and T.B. designed and supervised the research project, wrote the manuscript, and raised funds.

Conflict-of-interest disclosure: The authors declare no competing financial interests.

Correspondence: Tiziano Barbui, MD, Divisione di Ematologia, Ospedali Riuniti, Largo Barozzi 1, 24100 Bergamo, Italy; e-mail: tbarbui@ospedaliriuniti.bergamo.it.

\section{References}

1. Barbui T, Finazzi G. When and how to treat essential thrombocythemia. N Engl J Med. 2005; 353:85-86.

2. Vannucchi AM, Barbui T. Thrombocytosis and thrombosis. Hematology Am Soc Hematol Educ Program. 2007;2007:363-370.

3. Tefferi A, Gangat N, Wolanskyj AP. Management of extreme thrombocytosis in otherwise low-risk essential thrombocythemia; does number matter? Blood. 2006;108:2493-2494.

4. Barbui T, Barosi G, Grossi A, et al. Practice guidelines for the therapy of essential thrombocythemia. A statement from the Italian Society of $\mathrm{He}$ matology, the Italian Society of Experimental Hematology and the Italian Group for Bone Marrow Transplantation. Haematologica. 2004;89: 215-232.

5. Harrison CN. Essential thrombocythaemia: chal- lenges and evidence-based management. $\mathrm{Br}$ Haematol. 2005;130:153-165.

6. Carobbio A, Finazzi G, Guerini V, et al. Leukocytosis is a risk factor for thrombosis in essential thrombocythemia: interaction with treatment, standard risk factors, and Jak2 mutation status. Blood. 2007;109:2310-2313.

7. Vannucchi AM, Antonioli E, Guglielmelli $P$, et al Prospective identification of high-risk polycythemia vera patients based on JAK2(V617F) allele burden. Leukemia. 2007;21:19521959.

8. Pancrazzi A, Guglielmelli P, Ponziani V, et al. A sensitive detection method for MPLW515L or W515K mutation in chronic myeloproliferative disorders with locked nucleic acid-modified probes and real-time polymerase chain reaction. J Mol Diagn. 2008;10:435-441.
9. Di Nisio M, Barbui T, Di Gennaro L, et al. The haematocrit and platelet target in polycythemia vera. Br J Haematol. 2007;136:249259.

10. Elliott MA, Tefferi A. Thrombosis and haemorrhage in polycythaemia vera and essential thrombocythaemia. Br J Haematol. 2005;128: 275-290.

11. Girolami A, Tezza F, Scapin M, Vettore S, Casonato A. Arterial and venous thrombosis in patients with von Willebrand's disease: a critical review of the literature. J Thromb Thrombolysis. 2006;21:175-178.

12. Harrison CN, Campbell PJ, Buck G, et al. Hydroxyurea compared with anagrelide in high-risk essential thrombocythemia. N Engl J Med. 2005 353:33-45. 